
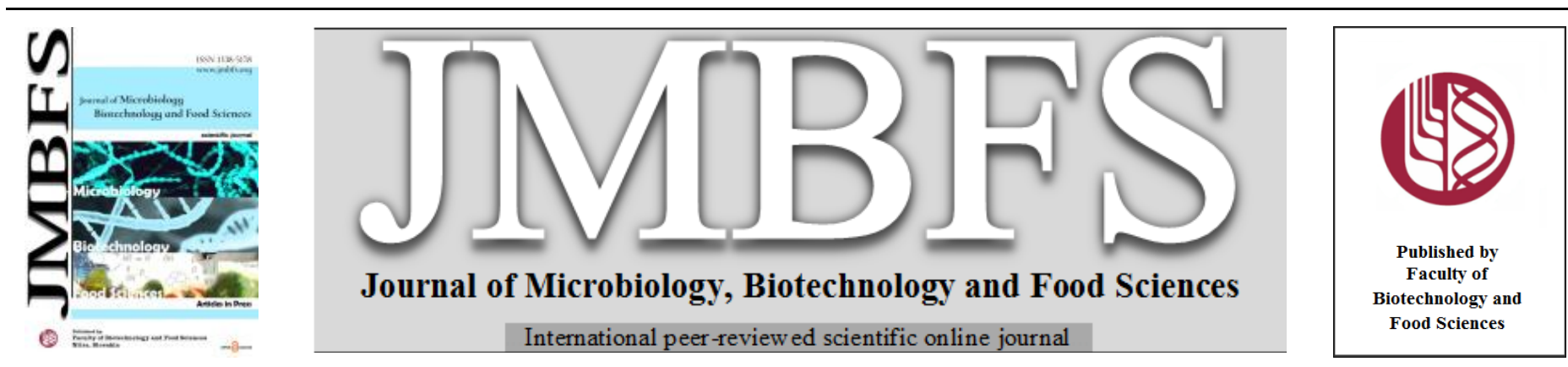

\title{
BIOENGINEERING OF THE CIRCULAR BACTERIOCIN FROM ENTEROCOCCUS FAECIUM NKR-5-3 BY NNK- SCANNING TO ENHANCE ITS BIOACTIVITY
}

\author{
Rodney H. Perez ${ }^{* 1}$, Riziel Hannah Aguimatang ${ }^{1}$, Takeshi Zendo ${ }^{2}$ and Kenji Sonomoto ${ }^{2}$
}

\section{Address(es):}

${ }^{1}$ National Institute of Molecular Biology and Biotechnology (BIOTECH), University of the Philippines Los Baños (UPLB), College, Laguna 4031 Philippines, Tel. No.: +63(049)-536-2721.

${ }^{2}$ Laboratory of Microbial Technology, Division of Applied Molecular Microbiology and Biomass Chemistry, Department of Bioscience and Biotechnology, Faculty of Agriculture, Graduate School, Kyushu University, Fukuoka, Japan.

*Corresponding author: rhperez@up.edu.ph

https://doi.org/10.15414/jmbfs.4309

\section{ARTICLE INFO}

Received 5. 2. 2021

Revised 29. 6. 2021

Accepted 1.7. 2021

Published 1. 12. 2021

$\underline{\text { Regular article }}$ OPEN $\partial_{\text {ACCESS }}$

\begin{abstract}
Bacteriocins are gene-encoded antimicrobial peptides that are traditionally appreciated as safe food preservative in the food industry and as possible alternative to conventional antibiotics in the pharmaceutical industry. Enterocin NKR-5-3B is a well characterized circular bacteriocin that possess exceptional stability due to the circular nature of its structure. In this paper, a mutant library of this bacteriocin was constructed through NNK-scanning whereby the presumed critical residues were targeted hoping to obtain bacteriocin derivatives with enhanced bioactivity. Thirteen (13) mutant phenotypes exhibited bioactivity enhancement relative to the native bacteriocin. The most notable bioactivity increases were observed from the phenotypes expressing V32C, V32A, and L40G that exhibited 233, 217, and $200 \%$ relative bioactivity, respectively. In-silico analyses of the resulting bacteriocin derivatives showed significant changes in the physico-chemical properties of the bacteriocin derivatives, particularly its hydrophobicity index, as a consequence of the introduced mutation. The V32C bacteriocin derivative which exhibited the strongest bioactivity enhancement was found to exhibit a reduction of the molecular surface hydrophobicity and isoelectric point. These changes may have contributed in the enhancement of its bioactivity. The identification of these critical mutations is highly valuable as basis for future studies on the rational design of bioengineered bacteriocins with enhanced bioactivity.
\end{abstract}

Keywords: lactic acid bacteria, bacteriocins, NNK-scanning, bacteriocin bioengineering

\section{INTRODUCTION}

Bacteriocins belong to a huge and diverse family of ribosomally synthesized bioactive peptides more commonly known as ribosomally synthesized and posttranslationally modified peptides (RiPPs) produced by a wide range of bacterial species (Arnison et al., 2013). The attention to RiPPs emanates from its higher amenability to bioengineering and the relative ease in setting up its scale-up systems compared to non-ribosomally synthesized bioactive compounds. Arguably, RiPPs from food-grade lactic acid bacteria (LAB), known as bacteriocins, are perhaps the most promising due to their diverse industrial utility as well as the general notion that LAB strains and their by-products are safe for human consumption. Bacteriocins have been traditionally appreciated for their utility in many food preservation-related technologies due to their potent bioactivity against common food spoilage and food-borne pathogens (Cotter $\boldsymbol{e}$ al., 2005). Additionally, the remarkable properties of bacteriocins such as high thermal stability, stable activity at wide $\mathrm{pH}$ range, and absence of organoleptic properties made them ideally suited in food-related applications. Nisin A and to a lesser extent pediocin PA-1/AcH, have been commercially utilized as food preservative in many food products in the US, Japan, Thailand, and most EU countries (Niamah, 2018). Recently, other areas of potential application of bacteriocins have been evaluated. Owing to the unique antimicrobial mechanism of bacteriocins that enable them to inhibit even the dreaded multi-drug resistant pathogens encouraged many scientists to explore their viability as alternative to conventional antibiotics (Cotter et al., 2013). The growing concern on the emergence of multi-drug resistant pathogens, coupled with the shrinking repertoire of effective antibiotics has triggered the desperate search for alternative antimicrobial agents. The continued research interest on bacteriocins resulted in the discovery of new-type of bacteriocins with diverse bioactivities. Some new bacteriocins were reported to show some potential as antiviral agents, as plant growth promoters, and as anti-cancer agents (Drider et al., 2016, Chikindas et al., 2018).
The biosynthesis of bacteriocins are relatively simpler compared to nonribosomally synthesized bioactive compounds. As a primary metabolite, the biosynthetic machinery of bacteriocins involves lesser number of genes than secondary metabolite bioactive compounds. This makes bacteriocins highly amenable to bioengineering. The introduction of site-directed mutagenesis into the gene encoding the bacteriocin precursor molecule could serve as a potential biological template for the production of novel peptides with improved functionalities (Cotter et al., 2006). For instance, the extensive bioengineering of lantibiotics, a group of bacteriocins that contain unusual amino acids, proved to be effective in obtaining new derivatives with improved bioactivities. The sitesaturation mutagenesis of nisin A yielded derivatives that exhibited enhanced potency (Field et al., 2008). Whereas the complete alanine scanning of all residues of lacticin 3147, a two-component lantibiotic, was shown to be a good template for rational drug design (Cotter et al., 2006). Site-directed mutagenesis of the lantibiotics, mutacin II and lacticin 481, provided information on the identification of residues responsible for the antimicrobial activities of these bacteriocins on the basis of the role of the residues on structure-function relationship of the bacteriocin molecule (Chen et al., 1998, Chatterjee et al., 2006, Dufour et al., 2007).

Meanwhile, enterocin NKR-5-3B is a novel circular bacteriocin produced as one of the five bacteriocins of Enterococcus faecium NKR-5-3 (Ishibashi et al., 2012, Perez et al., 2012). Circular bacteriocins are known for its remarkable stability to different stress as a result of the structurally conserved circular peptide backbone arising from the covalent linkage of their $\mathrm{N}$ - and C-terminal residues (Martin-Visscher et al., 2011, Perez et al., 2018). Enterocin NKR-5-3B is a well-characterized circular bacteriocin. It is synthesized from an 87-amino acid residue precursor peptide consisting of a 64-amino acid core peptide attached to a 23-amino acid N-terminal leader peptide. This precursor peptide would undergo post-translational modification catalyzed by its biosynthetic enzymes leading to the cleavage of the leader peptide and subsequent ligation of the terminal ends of the core peptide yielding a mature circular peptide. This bacteriocin has an average molecular mass of $6316.4 \mathrm{Da}$. The NMR solution 
structure of enterocin NKR-5-3B is characterized by four helical segments that enclose a tightly packed hydrophobic core, which together with its circular backbone structure, is the main stabilizing feature of the fold. Moreover, analysis of the NMR structure of the enterocin NKR-5-3B molecule identified some residues and regions that are potentially critical for its biological activity (Himeno et al., 2015)

The biosynthetic gene cluster of this circular bacteriocin has already been identified which is composed of five genes encoded as a single transcriptional unit. The gene cluster is composed of a gene that encodes the precursor peptide and four genes encoding the protein enzymes responsible for its biosynthetic processing, extra-cellular transport, and self-immunity. The heterologous expression system of enterocin NKR-5-3B was successfully established by cloning the five genes under the control of a powerful constitutive promoter. The resulting plasmid was termed pNK-B1234 (Perez et al., 2016).

In this present study, we attempted to bioengineer some potentially critical residues of this novel circular bacteriocin guided by the information from its three dimensional NMR solution structure (Himeno et al., 2015). Site-directed mutagenesis were genetically introduced into these residues through NNK scanning technique using the previously established heterologous expression plasmid of this bacteriocin as template. Here we report the identification of critical mutations that manifested strong enhancement of the bioactivity exhibited by the expressing phenotype. Our findings here provide information on the critical mutations in relation to bioactivity that could be used as basis for future studies on the rational design of enhanced bioactive peptides utilizing this circular bacteriocin as a scaffold.

\section{MATERIALS AND METHODS}

\section{Bacterial Strains and Culture Conditions}

Bacterial strains and plasmids used in this study are summarized in Table 1. The cloning host Escherichia coli DH5- $\alpha$, was cultivated in Luria-Bertani (LB) medium (Becton Dickinson, Sparks, MD) under constant agitation of 180 strokes $/ \mathrm{min}$ at $37^{\circ} \mathrm{C}$. The expression host Enterococcus faecalis $\mathrm{JH} 2-2$ was cultivated in M17 medium (Merck, Darmstadt, Germany) supplemented with $0.5 \%$ glucose (GM17) at $30^{\circ} \mathrm{C}$ for $24 \mathrm{~h}$. The indicator strain Lactococcus lacti subsp. lactis ATCC $19435^{\mathrm{T}}$ was cultivated in MRS medium (Oxoid, Hampshire, England) and in Lactobacilli Agar AOAC medium (Becton Dickinson), both at $30^{\circ} \mathrm{C}$, in liquid and solid culture, respectively. Chloramphenicol $(\mathrm{Cm})$ was used as antibiotic marker in selective medium at a final concentration of $10 \mu \mathrm{g} / \mathrm{ml}$. All strains were stored in $30 \%$ glycerol stock at $-80^{\circ} \mathrm{C}$ and revived twice before use.

$\underline{\text { Table } 1 \text { Bacterial strains and plasmids used in this study }}$

\begin{tabular}{|c|c|c|}
\hline Strain or plasmids & Description $^{a}$ & Source and/or reference ${ }^{b}$ \\
\hline \multicolumn{3}{|l|}{ Strain } \\
\hline Enterococcus faecium NKR-5-3 & Producer of enterocins NKR-5-3 & Ishibashi et al., 2012 \\
\hline Enterococcus faecalis $\mathrm{JH} 2-2$ & $\begin{array}{c}\text { Plasmid-free derivative of } \\
\text { E. faecalis JH-2 }\end{array}$ & Jacob \& Hobbs, 1974 \\
\hline Lactococcus lactis subsp. lactis ATCC $19435^{\mathrm{T}}$ & Indicator strain & ATCC \\
\hline Escherichia coli DH5 $\alpha$ & Plasmid cloning host & Novagen \\
\hline \multicolumn{3}{|l|}{ Plasmid } \\
\hline pMG36c & $\begin{array}{l}\text { pWV01-based cloning vector carrying a strong } \\
\text { Lactococcal promoter, } \mathrm{P}_{32}, \mathrm{Cm}^{\mathrm{r}}\end{array}$ & Kemperman et al., 2003 \\
\hline pNK-B1234 & $\begin{array}{l}\text { Enterocin NKR-5-3B heterologous expression } \\
\text { plasmid, skeletal plasmid from pMG36c, } \mathrm{Cm}^{\mathrm{r}}\end{array}$ & Perez et al., 2016 \\
\hline
\end{tabular}

${ }^{a} \mathrm{Cm}^{\mathrm{r}}$, chloramphenicol resistance.

${ }^{b}$ ATCC, American Type Culture Collection (Rockville, MD)

DNA Amplification and other Biotechnology Kits

PCR reactions were done using Q5 Cloning kit (New England Biolabs, MA USA). DNA amplicons and plasmids were purified and isolated using GeneAll DNA Purification Kit (GeneAll, South Korea). All DNA cloning and manipulations were done following standard methodology (Sambrook \& Russell, 2001).

Table 2 NNK primers used in the construction of the mutant library

\begin{tabular}{|c|c|c|c|}
\hline Primer Code & Sequence $\left(5^{\prime} \rightarrow 3^{\prime}\right)^{a}$ & $\operatorname{Tm}\left({ }^{\circ} \mathrm{C}\right)^{b}$ & $\begin{array}{l}\text { Reverse } \\
\text { Primer }\end{array}$ \\
\hline V25NNK-F & AGCGCANNKGCTACAATCATTGCTCTTGTCACTGC & 68 & \multirow{9}{*}{ NNK-R1 } \\
\hline A26NNK-F & AGCGCAGTCNNKACAATCATTGCTCTTGTCACTGC & 69 & \\
\hline T27NNK-F & AGCGCAGTCGCTNNKATCATTGCTCTTGTCACTGC & 70 & \\
\hline I28NNK-F & AGCGCAGTCGCTACANNKATTGCTCTTGTCACTGC & 70 & \\
\hline I29NNK-F & AGCGCAGTCGCTACAATCNNKGCTCTTGTCACTGC & 71 & \\
\hline A30NNK-F & AGCGCAGTCGCTACAATCATTNNKCTTGTCACTGC & 68 & \\
\hline L31NNK-F & AGCGCAGTCGCTACAATCATTGCTNNKGTCACTGC & 70 & \\
\hline V32NNK-F & AATCATTGCTCTTNNKACTGCTGTTGTTGGAG & 61 & \\
\hline T33NNK-F & AATCATTGCTCTTGTCNNKGCTGTTGTTGGAG & 64 & \\
\hline A34NNK-F & AATCATTGCTCTTGTCACTNNKGTTGTTGGAG & 62 & \multirow{3}{*}{ NNK-R2 } \\
\hline V35NNK-F & AATCATTGCTCTTGTCACTGCTNNKGTTGGAG & 63 & \\
\hline V36NNK-F & AATCATTGCTCTTGTCACTGCTGTTNNKGGAG & 63 & \\
\hline G37NNK-F & GCTGTTGTTNNKGGCGGCTTGATTACAGC & 64 & \multirow{5}{*}{ NNK-R3 } \\
\hline G38NNK-F & GCTGTTGTTGGANNKGGCTTGATTACAGC & 62 & \\
\hline G39NNK-F & GCTGTTGTTGGAGGCNNKTTGATTACAGC & 62 & \\
\hline L40NNK-F & GCTGTTGTTGGAGGCGGCNNKATTACAGC & 65 & \\
\hline I41NNK-F & GCTTGNNKACAGCTGGGATTGTTGCTACAGC & 65 & \\
\hline T42NNK-F & GCTTGATTNNKGCTGGGATTGTTGCTACAGC & 64 & \multirow[t]{6}{*}{ NNK-R4 } \\
\hline A43NNK-F & GCTTGATTACANNKGGGATTGTTGCTACAGC & 62 & \\
\hline NNK-R1 & ACCAGTATTAATTATGTCAATAACTTTTTTTGCTGC & 61 & \\
\hline NNK-R2 & GTAGCGACTGCGCTACCAGTATTAATTATGTC & 63 & \\
\hline NNK-R3 & AGTGACAAGAGCAATGATTGTAGCGACTGC & 65 & \\
\hline NNK-R4 & CGCCTCCAACAACAGCAGTGACAAGAGC & 67 & \\
\hline
\end{tabular}

\section{Construction of NNK Plasmids}

The substitution mutagenesis of selected residues of the enterocin NKR-5-3B molecule was genetically introduced into the bacteriocin structure gene by round
PCR using two outward-facing primers wherein the native codons of the target residue were replaced with an NNK triplet nucleotide (whereby $\mathrm{N}$ is any nucleotide and $\mathrm{K}$ is either guanine or thymine). The list of primers is summarized in Table 2. The use of NNK minimizes the unnecessary and wanted introduction 
of stop codon and improves codon usage to theoretically cover all 20 standard amino acids (Cwirla et al., 1990, Scott \& Smith, 1990). The heterologous expression plasmid of this circular bacteriocin, pNKB1234, was used as template DNA for every PCR reaction. In order to minimize unwanted unspecific PCR amplicons, the PCR reaction condition for each target residue was optimized by adjusting the $\mathrm{Mg}^{2+}$ ion concentration and annealing temperatures. Each PCR product was ligated after purification and subsequently utilized for the electrotransformation of the cloning and expression host accordingly.Screening of

\section{Representative of the Mutant Library}

In order to screen for the representative composition of the mutant library, one hundred colonies from the electro-transformed E. coli DH5- $\alpha$ were randomly selected for every mutated position. Selected transformants were then cultured and the corresponding plasmids were isolated and were submitted for DNA sequencing to identify the introduced mutation. A plasmid that has a mutation corresponding to each standard amino acid was chosen for every target residue and was subsequently introduced to the expression host E. faecalis $\mathrm{JH} 2-2$ by electro-transformation.

\section{Bioactivity Evaluation of Mutant Phenotypes}

The antimicrobial activities of each bacteriocin derivative was determined using a modified colony overlay method as described previously by Miller $\boldsymbol{e t}$ al., (1998). Briefly, an overnight culture of each mutant phenotype was spotted using a sterile toothpick on a GM17 agar plate and incubated overnight at $30^{\circ} \mathrm{C}$. After incubation, the agar plates were air-dried under the clean-bench and $8 \mathrm{~mL}$ molten Lactobacilli agar AOAC (Becton Dickinson) containing 1\% (v/v) of actively growing overnight culture of the indicator strain Lactococcus lactis ATCC $19435^{\mathrm{T}}$ was then overlaid onto the plate and incubated at $30^{\circ} \mathrm{C}$ overnight. This indicator strain is the most sensitive to enterocin NKR-5-3B and hence should be able to detect even minor change in the bacteriocin bioactivity (Himeno et al., 2015). Bioactivities of the mutant colonies were assessed by measurement of the inhibition zone diameter surrounding the colonies after incubation. The relative bioactivity was calculated by taking the average zone diameter of four spots in the case of each mutant phenotype on different plates and dividing the average zone diameter by that of the wild type and multiplied by 100 .

\section{Purification of Bacteriocin Derivatives}

The purification of bacteriocin derivatives were carried out following the previously reported purification scheme of the native enterocin NKR-5-3B (Perez et al., 2016). Briefly, it was done through a 3 -step chromatographic procedure from the culture supernatants of their respective mutant phenotypes previously cultured in a $250 \mathrm{~mL}$ GM17 medium grown for $20 \mathrm{~h}$ at $30^{\circ} \mathrm{C}$. The active component from the cell-free supernatant were allowed to bind to a $10 \mathrm{~g}$ of activated Amberlite XAD-16N (Sigma-Aldrich, St Louis, MO, USA) synthetic hydrophobic resin by soaking it overnight with gentle shaking. The resins were repeatedly washed with $40 \%$ ethanol to remove media-borne impurities. The bacteriocins were eluted using $70 \%$ isopropanol acidified with $0.1 \%$ trifluoroacetic acid (TFA), which was then vacuum evaporated to remove the alcohol. The resulting solution was then loaded to a strong cation-exchange resin, SP-Sepharose Fast Flow (GE Healthcare, Uppsala, Sweden) pre-activated with $50 \mathrm{mM}$ phosphate buffer (PB, pH 5.6). The column was then washed with the same PB buffer and the bacteriocin was eluted using PB buffer with $1.0 \mathrm{M} \mathrm{NaCl}$. Final purification of the bacteriocin fraction was done using a reverse-phase column (Resource RPC 3-ml; GE Healthcare) attached to an LC-2000Plus HPLC system (Jasco, Tokyo, Japan). The bacteriocin was eluted using a gradient mobile phase of MilliQ water-acetonitrile acidified with $0.1 \%$ TFA at a flow rate of 1 $\mathrm{ml} / \mathrm{min}$. In order to remove the acetonitrile and at the same time concentrate the bacteriocin, the fractions were applied to a Speed-Vac Concentrator (Savants, Farmingdale, NY, USA).

\section{Molecular Weight Confirmation of the Bacteriocin Derivative}

In order to confirm the identity of the bacteriocin derivatives, 5-10 $\mu 1$ aliquot of each of the purified bacteriocins was analyzed using a JMS-T100LC electrospray ionization time-of-flight mass spectrometry system, (ESI-TOF MS; JEOL, Tokyo, Japan) determining their respective molecular weight (MW) (Perez et al, 2017). The MW of each bacteriocin derivative was calculated from the most dominant charged ion form in the total mass spectra. The observed MW of each bacteriocin derivative was compared with the theoretical MW deduced from its amino acid sequence minus $18 \mathrm{Da}$ as a consequence of the $\mathrm{N}$ - and $\mathrm{C}$ - terminal ligation forming the circular structure.

\section{In-silico Analysis of Bacteriocin Derivatives}

Analysis of the DNA sequence of each mutants was done using the GENETYXWIN software Ver. 8.0.1 (GENETYX, Tokyo, Japan). The identity of each substitution mutations was confirmed based on the translated amino acids from each DNA sequence. Possible frame-shift mutations were checked for the entire biosynthetic gene cluster. The three-dimensional structures of the bacteriocinderivatives were modeled using the SWISS-MODEL server, using the NMR solution structure of the native enterocin NKR-5-3B (PDB entry: 2mp8) as template, to examine the effect of the mutation on the secondary structure of the molecule of the bioengineered derivatives. Further secondary structure assessment of the models was also used to identify the possible changes on the helices of the bacteriocin molecules. The images were rendered using PyMoL Molecular Graphics system. Other physico-chemical properties of each bacteriocin derivatives were obtained using GeneScript ${ }^{\circledR}$ Peptide Property Tool and ExPaSy ProtParam Tool.

\section{RESULTS AND DISCUSSION}

\section{Enterocin NKR-5-3B Mutant Library}

The previously reported three-dimensional solution structure of enterocin NKR$5-3 \mathrm{~B}$ revealed that the residues at the $2^{\text {nd }}$ helix region (spanning from V25 to V35) and the inter-helix region (V36 to A43) were found to be highly dynamic which is indicative that these regions are potentially critical for its bioactivity (Himeno et al., 2015). In this study, the residues in these regions were individually targeted for random substitution mutagenesis through NNK scanning. Of the total 1,900 colonies (100 colonies for every mutated position) picked and examined by DNA sequencing, 267 mutants were selected to comprise the mutant library (Figure 1). Three hundred eighty (380) mutants were the expected composition of the mutant library, however, representative mutations at some positions were not obtained due to the random nature of NNK mutagenesis. For instance, when L31 and V36 positions were mutated, only 8 and 10 mutations were obtained, respectively. The positions V25, A26, L40 and T42 yielded the most mutant representations. Fifteen representative mutations were obtained at the V25, L40, and T42 while sixteen mutants were obtained at A26 position. The mutant library was clustered based on the chemical properties of the amino acid substitution to facilitate data interpretation.

\section{Mutant Phenotypes with Enhanced Bioactivity}

Of the 267 mutants, 13 mutant phenotypes exhibited higher bioactivity compared to that of the native enterocin NKR-5-3B expressing phenotype. Whereas 11 mutant phenotypes exhibited comparable bioactivity to the native bacteriocin expressing phenotype (Figure 1). The V32C, V32A, and L40G expressing phenotypes exhibited the strongest enhancement of its bioactivity showing 233 , 217 , and $200 \%$ relative bioactivity (Figures 1 and 2). Whereas the phenotypes expressing the V32G, V35N, V25M, V25T, L40A, and T33S derivatives showed a modest enhancement of their bioactivities ranging from 150 to $183 \%$ bioactivity relative to the native bacteriocin expressing phenotype. The L40M, T42E, L40S, and V25S expressing phenotypes showed slight enhancement of their bioactivity that ranged from 120 to $140 \%$ relative bioactivity (Figures 1 and 2). This is the first report that describe the bioengineering of a circular bacteriocin, perhaps due to the limited information on the molecular details of the biosynthetic machinery of circular bacteriocins (Perez et al., 2018). Thus far, only bacteriocins belonging to the lantibiotics family have been subjected to extensive bioengineering to enhance its bioactivities. Bioengineering of nisin $\mathrm{A}$ at the "hinge" region of its molecule with small chiral amino acids, such as Ala, Leu, and Ile resulted to a nisin derivative that showed two-fold enhancement in its bioactivities against pathogenic strains Staphylococcus aureus RF122 and Streptococcus agalactiae ATCC 13813 (Healy et al., 2013). Mutations at the $29^{\text {th }}$ position of nisin A yielded some promising variants such as Ser29Gly and Ser29Ala, which exhibited a two-fold increase in potency against the clinically important strains methicillin-resistant Staphylococcus aureus (MRSA), and vancomycin resistant enterococci (VRE) (Field et al., 2012). Moreover, Lys12Ala mutations of nisin A showed improved specific activity towards MRSA ST528 and VRE EC533 (Molloy et al., 2013). The lantibiotic nukacin ISK-1 when subjected to a substitution mutagenesis yielded a number of derivatives that showed enhanced bioactivities. The phenotype expressing D13E nukacin derivative showed more than two-fold increase in its bioactivity against the indicator strain (Islam et al., 2009). 


\begin{tabular}{|c|c|c|c|c|c|c|c|c|c|c|c|c|c|c|c|c|c|c|c|c|c|}
\hline & \multicolumn{20}{|c|}{ Amino acid residue substitution / Relative bioactivity (\%) } \\
\hline & & \multicolumn{4}{|c|}{ Aliphatic, hydrophobic } & \multicolumn{3}{|c|}{ Aromatic, hydrophobic } & \multicolumn{6}{|c|}{ Neutral side chain } & \multicolumn{3}{|c|}{$\begin{array}{l}\text { Positively charged } \\
\text { side chain }\end{array}$} & \multicolumn{2}{|c|}{$\begin{array}{l}\text { Negatively } \\
\text { charged side chain }\end{array}$} & \multicolumn{2}{|c|}{$\begin{array}{l}\text { Unique amino } \\
\text { acid }\end{array}$} \\
\hline & & A & 1 & L & v & $\mathbf{F}$ & w & $\mathrm{Y}$ & $\mathrm{N}$ & c & $Q$ & M & s & T & $\mathbf{R}$ & $\mathrm{H}$ & K & D & $\mathrm{E}$ & G & $\mathbf{P}$ \\
\hline \multirow{11}{*}{ 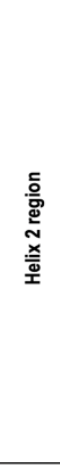 } & V25 & & 16 & 16 & WT & 16 & 16 & 16 & & 16 & 16 & 180 & 120 & 180 & 16 & & & 16 & & 16 & 16 \\
\hline & A26 & WT & 16 & 16 & 100 & 16 & & 16 & 16 & 83 & 100 & 16 & & 16 & 16 & 16 & & & 16 & 16 & 16 \\
\hline & T27 & 16 & & 16 & & 16 & 16 & & 16 & 16 & 16 & & 16 & WT & 16 & 16 & & & 16 & 16 & \\
\hline & 128 & 100 & WT & & 16 & & 16 & 16 & & 16 & & & 100 & & 16 & & 16 & & & 16 & 16 \\
\hline & 129 & & WT & & & & & 16 & & 16 & 16 & & 16 & & 16 & & 16 & 16 & & 16 & 16 \\
\hline & A30 & WT & & 100 & & 16 & 16 & & & 16 & & 16 & & & 16 & & 16 & & 16 & & 16 \\
\hline & L31 & & 83 & WT & & & & 16 & & 16 & 16 & & & 16 & & & 16 & & & 16 & \\
\hline & V32 & 217 & 83 & 16 & WT & 16 & & & 16 & 233 & 16 & & 16 & & 16 & & & & 100 & 183 & 16 \\
\hline & T33 & 16 & 16 & & 16 & & 16 & & & 50 & 16 & & 150 & WT & 16 & 83 & 16 & 16 & 16 & & \\
\hline & A34 & WT & & 16 & & & 16 & & 16 & & 16 & 16 & & 16 & 16 & 16 & & 16 & & 16 & 16 \\
\hline & V35 & & 16 & 16 & WT & 16 & & 16 & 180 & 50 & & 16 & & 83 & & 100 & & & & 42 & \\
\hline \multirow{8}{*}{ 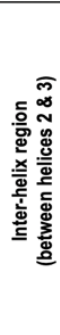 } & V36 & & 16 & & WT & 16 & 16 & 16 & 16 & & & 16 & & 16 & & & & & & 16 & 16 \\
\hline & G37 & & & 16 & 16 & 16 & 16 & 16 & & 16 & & 16 & 16 & & 16 & & & 16 & 16 & WT & \\
\hline & G38 & 16 & 16 & 16 & 16 & 16 & 16 & 16 & & 16 & & 16 & 16 & 16 & 16 & & & 83 & 16 & WT & \\
\hline & G39 & 16 & & 16 & 16 & 16 & 16 & 16 & & 16 & 16 & 16 & 100 & & 16 & & & & & WT & 16 \\
\hline & L40 & 160 & 16 & WT & 100 & 100 & & & 16 & 16 & & 140 & 120 & & 16 & & 16 & 16 & 16 & 200 & 16 \\
\hline & 141 & & WT & 16 & 16 & 16 & 16 & 16 & & 16 & & 80 & 16 & 16 & 16 & & & 16 & 16 & 100 & \\
\hline & T42 & 16 & 16 & 16 & 16 & & 16 & 16 & & 16 & & 16 & 16 & WT & 16 & & & 16 & 140 & 16 & 16 \\
\hline & A43 & WT & & & 16 & & & 16 & & & & 16 & 16 & 16 & 16 & 16 & & & 16 & 16 & 16 \\
\hline
\end{tabular}

Figure 1 Relative bioactivity profile of the enterocin NKR-5-3B mutant library. Black panels indicate enhanced bioactivity; dark grey panels indicate unchanged bioactivity. Blank panels indicate that representative mutants were not obtained from the 100 selected colonies. The location of the residues with regards to the secondary structure orientation of the bacteriocin molecule is indicated. The chemical properties of the amino acid substitution are also indicated to facilitate data interpretation

\section{Growth Profiles of the Mutant Phenotypes}

In general, the mutant phenotypes and the native enterocin NKR-5-3B (pNKB1234) expressing phenotype exhibited similar growth profiles with the exception of the V32G expressing mutant phenotype, which manifested a slightly lower growth (Figure 3). The growth behavior of these phenotypes indicates that the enhancement of the bioactivity of the bacteriocin derivatives had little effect on the general metabolic activity of the producer strains. Furthermore, it can be deduced that the self-immunity modules encoded in the biosynthetic gene cluster of enterocin NKR-5-3B can still offer protection to the expressing host strain from the inhibitory action of the bacteriocin derivatives.

\section{Purification Behavior of Bacteriocin Derivatives}

The bacteriocin derivatives that manifested enhanced bioactivities were purified from their respective mutant phenotypes according to the established purification system of the native enterocin NKR-5-3B. Interestingly the retention time of the bacteriocin derivatives in general have decreased suggesting a significant alteration of the physico-chemical properties of the bacteriocin derivatives. The native form of enterocin NKR-5-3B was eluted around $17.7 \mathrm{~min}$ using the earlier reported HPLC purification condition. However, the elution time of most derivatives were relatively earlier than that of the native bacteriocin. For instance, the V32C and V25S derivatives were both eluted at a much earlier time of 10.9 $\mathrm{min}$. Whereas, L40S and L40A derivatives were eluted at $11.6 \mathrm{~min}$ and $12.2 \mathrm{~min}$, respectively. Only the derivatives V32G (17.8 $\mathrm{min})$ and $\mathrm{V} 35 \mathrm{~N}(17.6 \mathrm{~min})$ were eluted at around similar time with the native enterocin NKR-5-3B (Table 3).
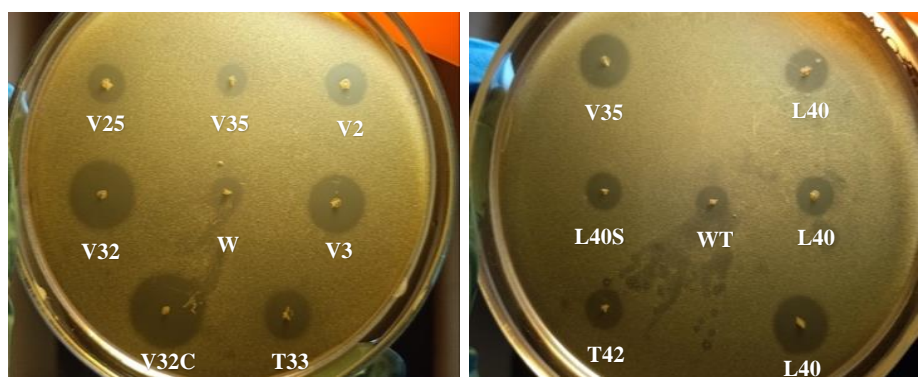

Figure 2 Mutant phenotypes producing enterocin NKR-5-3B derivatives that exhibited enhanced bioactivity. Bioactivity of the phenotypes was visualized through colony overlay assay using Lactococcus lactis subsp. lactis ATCC $19435^{\mathrm{T}}$ as indicator strain. The identity of the mutant phenotypes is indicated under each colonies. The native bacteriocin (WT) is produced through the previously reported heterologous expression plasmid pNK-B1234 (Perez $\boldsymbol{e t}$ al., 2016).
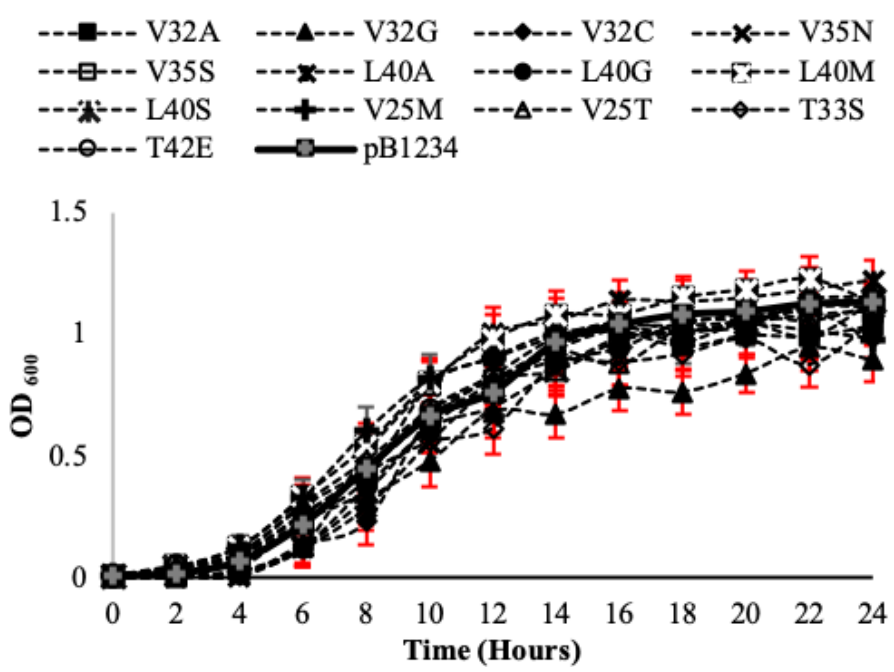

Figure 3 Growth profile monitoring of the phenotypes (Enterococcus faecalis $\mathrm{JH} 2-2$ as the heterologous host) expressing the bacteriocin derivatives and native enterocin NKR-5-3B (pB1234) for $24 \mathrm{~h}$. Data represent the average from 2 replications \pm standard deviation.

\section{ESI-MS Spectra of the Bacteriocin Derivatives}

The ESI-MS spectra of the bacteriocin derivatives that showed enhanced bioactivity are shown in Figure 4. The most dominant ion form of all derivatives was in quadruple charged ions, $[\mathrm{M}+4 \mathrm{H}]^{4+}$, to which the observed molecular weight of each bacteriocin derivative was calculated. The observed molecular weight of the bacteriocin derivatives were very close (difference of around $1 \mathrm{Da}$ ) to the respective theoretical molecular weights of each bacteriocin derivatives. This data further confirms the correct identity of the bacteriocin derivatives. 
Table 3 Physico-chemical properties of enterocin NKR-5-3B enhanced derivatives

\begin{tabular}{|c|c|c|c|c|c|}
\hline \multirow[b]{2}{*}{ Name of Derivative } & \multicolumn{3}{|c|}{ Peptide Property } & \multirow[b]{2}{*}{ Retention Time (min) } & \multirow[b]{2}{*}{ Relative Bioactivity ${ }^{d}$} \\
\hline & $\mathrm{pI}^{a}$ & Net Charge ${ }^{a}$ & $\begin{array}{l}\text { Hydrophobicity }^{b} \\
\text { (GRAVY Index) }^{c}\end{array}$ & & \\
\hline Ent53B (WT) & 10.47 & 4 & 0.953 & 17.7 & 100 \\
\hline V25T & 10.47 & 4 & 0.877 & 15.4 & 180 \\
\hline V25S & 10.47 & 4 & 0.875 & 10.9 & 120 \\
\hline V25M & 10.47 & 4 & 0.917 & 12.5 & 180 \\
\hline $\mathrm{V} 32 \mathrm{~A}$ & 10.47 & 4 & 0.916 & 16.6 & 217 \\
\hline V32G & 10.47 & 4 & 0.881 & 17.8 & 183 \\
\hline V32C & 10.24 & 4 & 0.927 & 10.9 & 230 \\
\hline T33S & 10.47 & 4 & 0.952 & 16.6 & 150 \\
\hline V35N & 10.47 & 4 & 0.883 & 17.6 & 133 \\
\hline L40A & 10.47 & 4 & 0.922 & 12.2 & 160 \\
\hline L40S & 10.47 & 4 & 0.881 & 11.6 & 120 \\
\hline L40G & 10.47 & 4 & 0.887 & 12.9 & 200 \\
\hline L40M & 10.47 & 4 & 0.923 & 13.4 & 140 \\
\hline $\mathrm{T} 42 \mathrm{E}$ & 10.47 & 3 & 0.909 & 15.5 & 140 \\
\hline
\end{tabular}

a predicted for the circular form of the bacteriocin using GeneScript Peptide Property Tool

$\underline{b}$ predicted for the linear form of the bacteriocin using ExPaSy ProtParam Tool

$\subseteq$ Grand Average of Hydropathy

$\underline{d}$ bioactivity against L. lactis subsp. lactis ATTCC $19435^{\mathrm{T}}$

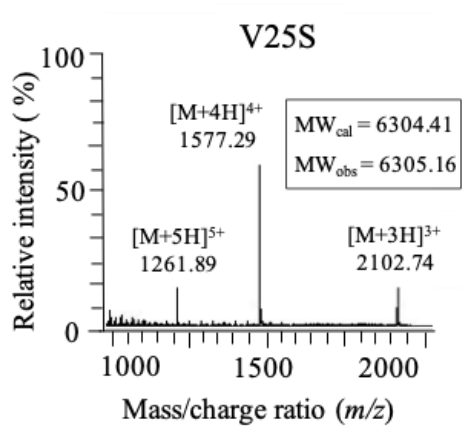

$\mathrm{V} 32 \mathrm{C}$

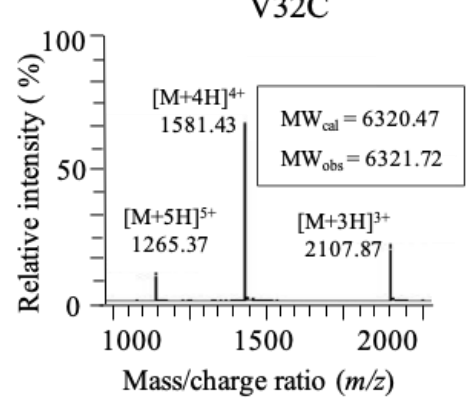

L40A

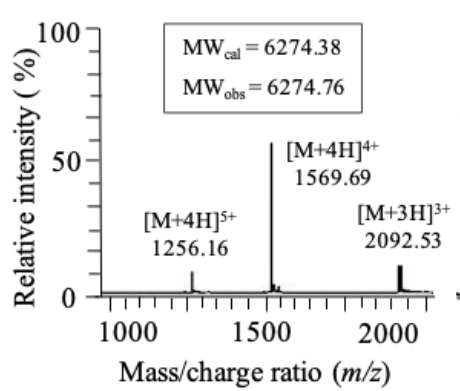

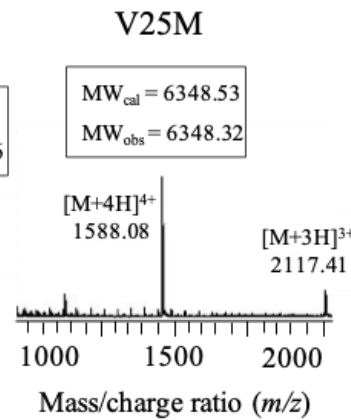

T33S

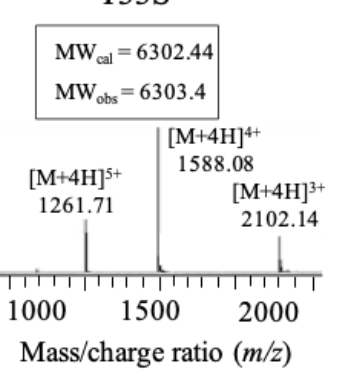

V25T

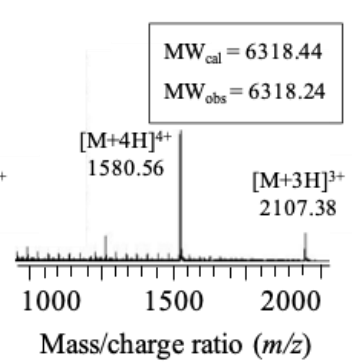

V35N

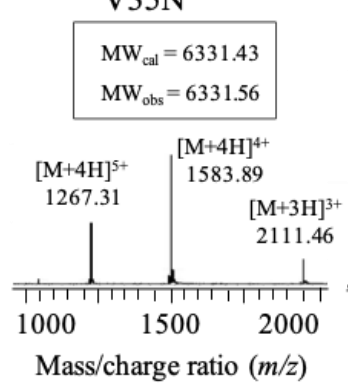

V32A

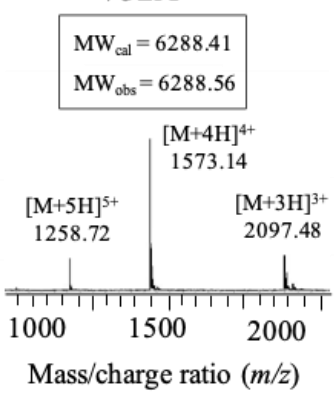

L40G

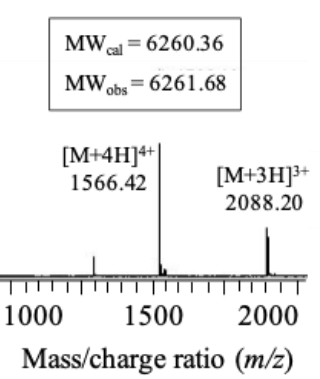

V32G

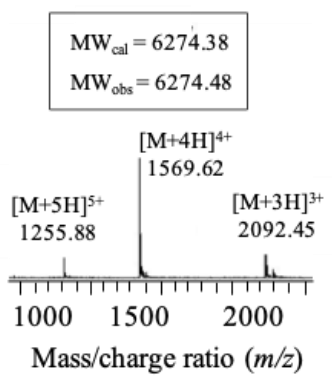

L40S

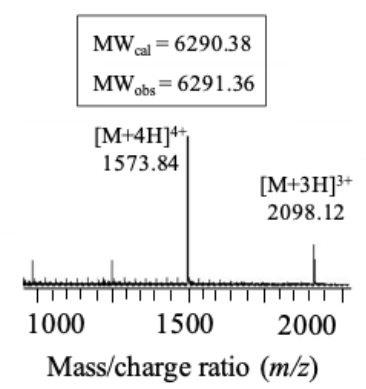

Figure 4 ESI-TOF mass spectra of enterocin NKR-5-3B derivatives with enhanced bioactivity relative to its native form. Detected multiple charge ions of each bacteriocin derivative are indicated. Calculated and observed MWs are indicated in the inset of each panel. Observed MWs were calculated from the most abundant ion species (quadruple charged).

\section{In-silico Physico-chemical Analyses of the Bacteriocin Derivatives}

The physico-chemical properties of the enhanced derivatives such as isoelectric point (pI), net charge, and hydrophobicity (Grand Average of Hydropathy, GRAVY index), which were obtained by submitting their amino acid sequences to peptide analytic databases GeneScript Peptide Property Tool and ExPaSy ProtParam tool are shown in Table 3. The pI and net charge of the bacteriocin derivatives were predicted in their circular forms whereas the GRAVY indices were obtained in their linear forms. The isoelectric point and net charge of most of the bacteriocin derivatives were not affected by the mutation. Only the V32C derivative manifested a change in its isoelectric point of 10.24 while the rest of the derivatives have the same pI with that of the native enterocin NKR-53B which is at 10.47 . Whereas, only the T42E derivative showed a reduction of its net charge which is at $3^{+}$while the rest of the derivatives had a comparable net charge with that of the native enterocin NKR-5-3B. 
However, unlike the isoelectric point and net charge, the hydrophobicity values of the bacteriocin derivatives showed significant change as a consequence of the introduced mutations. The GRAVY indices of the bacteriocin derivatives with enhanced bioactivity generally decreased. Most notably, the derivatives V32G and L40S showed the biggest decrease on their GRAVY indices. Only the T33S derivative showed comparable GRAVY index to its native form. The native enterocin NKR-5-3B and T33S have GRAVY index of 0.953 and 0.952 , respectively.

The relationship of the change in the hydrophobicity and the enhancement of the bioactivity of resulting bacteriocin derivative is rather inconsistent (Table 3). The most plausible reason for this observation is that the GRAVY index represents only the overall hydrophobicity of the molecule rather than surface hydrophobicity of the molecule. For instance, direct comparison of the GRAVY indices of V32C $(0.927)$ and $\mathrm{V} 35 \mathrm{~N}(0.883), \mathrm{V} 35 \mathrm{~N}$ would appear to be less hydrophobic than $\mathrm{V} 32 \mathrm{C}$, however, examining the 3D structure model of these derivatives show that the latter had more solvent exposed region. The neural side chain of cysteine at P32' is more exposed than that of the neutral side chain of asparagine at P35' (Figure 5). In general, the bacteriocin derivatives that exhibited strong enhancement of bioactivity had less pronounced hydrophobic patches in its surface compared to the native form of the bacteriocin. The reduction of the surface hydrophobicity of the molecule may have enhanced the ability of the molecule to interact with the membrane surface of the target strains. In the case of $\mathrm{V} 32 \mathrm{C}$ derivative, in addition to the decrease in its surface hydrophobicity, a reduction of its isoelectric point was also apparent. These changes may have affected the solubility of the molecule resulting to the strong enhancement of its bioactivity. Among the mutant derivatives, the V32C expressing phenotype exhibited strongest bioactivity enhancement (230\%).
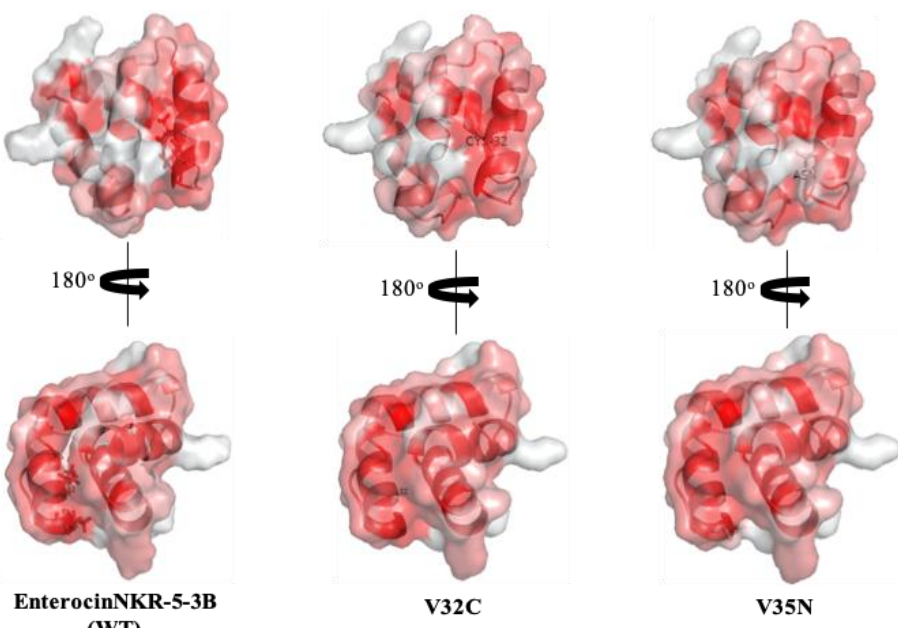

(WT)

Figure 5 Hydrophobic surface maps of the bacteriocin derivatives $\mathrm{V} 32 \mathrm{C}$ and V35N and its native bacteriocin form, enterocin NKR-5-3B. Red indicates hydrophobic residues and white represents hydrophilic resides. The color intensity indicates the hydrophobicity or hydrophilicity of the residues. The 3D models of the bacteriocin derivatives were generated using the Swiss Protein Modelling Server (https://swissmodel.expasy.org) using the NMR solution structure data of enterocin NKR-5-3B (PDB entry: 2mp8) as template. Images are generated using PyMol Molecular Graphics System. The images are rendered in such a way that the secondary structure orientation of the molecule is also visible.

\section{In-silico Structure Analysis and Modeling of Bacteriocin Derivatives}

The bacteriocin derivatives did not manifest any significant changes in the overall secondary structure orientation of their molecules. In particular, the introduced mutations did not affect the positions of helix 2 and interhelix region which are still located at P'25 to P'35 and P'36 to P'43, respectively based on the secondary structure prediction model of these bacteriocin derivatives (Figure 6) This result supports the above-mentioned notion that the enhancement of the bioactivities of the bacteriocin derivatives is a consequence to the changes in the physico-chemical property of the bacteriocin molecule rather than as a consequence to the alteration of its overall structure conformation.

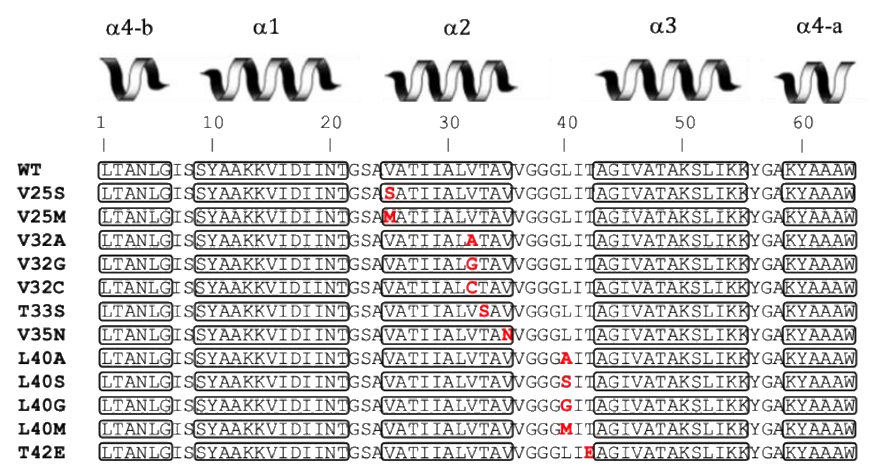

Figure 6 In-silico secondary structure analysis of the bacteriocin derivatives with enhanced bioactivity. Specific mutation of each derivative is indicated in red. The secondary helices of the bacteriocin molecule are indicated in numbered cartoon structure and oval shape overlay in the amino acid sequence of the bacteriocin derivatives.

\section{CONCLUSION}

In the present study, we report the establishment of the mutant library of enterocin NKR-5-3B in which 13 phenotypes expressing the bacteriocin derivatives exhibited strong enhancement of its bioactivity. These bacteriocin derivatives would be highly useful in the future utilization of these bacteriocins in different industries. Information on the critical mutations would be very helpful in the future studies on the rational design of bacteriocins with enhanced bioactivity.

Acknowledgements: The work described here was supported in part by the Japan Society for the Promotion of Science (JSPS) and the Enhanced Creative Work Research Grant (ECWRG-2019-2-21-R) of the Office of Vice President for Academic Affairs (OVPAA) of the University of the Philippines System.

\section{REFERENCES}

Arnison, P.G., M.J. Bibb, G. Bierbaum, A.A. Bowers, T.S. Bugni, G. Bulaj, et al (2013) Ribosomally synthesized and post-translationally modified peptide natural products: overview and recommendations for a universal nomenclature. Natural Product Reports 30: 108-160. http://dx.doi.org/10.1039/c2np20085f.

Chatterjee, C., G.C. Patton, L. Cooper, M. Paul, \& W.A. van der Donk, (2006) Engineering dehydro amino acids and thioethers into peptides using lacticin 481 synthetase. Chemical Biolology.13(10):

1109-1117. http://dx.doi.org/10.1016/j.chembiol.2006.08.015.

Chen, P., J. Novak, M. Kirk, S. Barnes, F. Qi, \& P.W. Caufield, (1998) Structureactivity study of the lantibiotic mutacin II from Streptococcus mutans T8 by a gene replacement strategy. Applied Environmental Microbiology 64(7): 23352340. http://dx.doi.org/10.1128/AEM.64.7.2335-2340.1998.

Chikindas, M.L., R. Weeks, D. Drider, V.A. Chistyakov, \& L.M. Dicks, (2018) Functions and emerging applications of bacteriocins. Current Opinion on Biotechnology 49: 23-28. http://dx.doi.org/10.1016/j.copbio.2017.07.011.

Cotter, P.D., C. Hill, \& R.P. Ross, (2005) Bacteriocins: developing innate immunity for food. Nature Reviews Microbioliology 3: 777-788. http://dx.doi.org/10.1038/nrmicro1273.

Cotter, P.D., L.H. Deegan, E.M. Lawton, L.A. Draper, P.M. O’Connor, C. Hill \& R.P. Ross, (2006) Complete alanine scanning of the two-component lantibiotic lacticin 3147: Generating a blueprint for rational drug design. Molecular Microbiology 62(3):735-47. http://dx.doi.org/10.1111/j.1365-2958.2006.05398.x. Cotter, P.D., R.P. Ross, \& C. Hill, (2013) Bacteriocins - a viable alternative to antibiotics? Nature Reviews Microbioliology 11: 95-105. http://dx.doi.org/10.1038/nrmicro2937.

Cwirla, S.E., E.A. Peters, R.W. Barrett, \& W.J. Dower, (1990) Peptides on phage: A vast library of peptides for identifying ligands. Proceedings of the National Academy of Science United States of America 87(16): 6378-6382 http://dx.doi.org/10.1073/pnas.87.16.6378

Drider, D., F. Bendali, K. Naghmouchi, \& M.L. Chikindas, (2016) Bacteriocins: Not only antibacterial agents. Probiotics Antimicrobial Proteins 8: 177-182 http://dx.doi.org/10.1007/s12602-016-9223-0.

Dufour, A., T. Hindré, D. Haras, \& J.P. Le Pennec, (2007) The biology of lantibiotics from the lacticin 481 group is coming of age. FEMS Microbiology Reviews 31(2): 134-167. http://dx.doi.org/10.1111/j.1574-6976.2006.00045.x.

Field, D., M. Begley, P.M. O’Connor, K.M. Daly, F. Hugenholtz, P.D. Cotter, C Hill, \& R.P. Ross, (2012). Bioengineered Nisin A derivatives with enhanced activity against both Gram positive and Gram negative pathogens. PLoS One. http://dx.doi.org/10.1371/journal.pone.0046884.

Field, D., P.M. O.' Connor, P.D. Cotter, C. Hill, \& R.P. Ross, (2008) The generation of nisin variants with enhanced activity against specific Gram-positive 
pathogens. Molecular Microbiology http://dx.doi.org/10.1111/j.13652958.2008.06279.x.

Healy, B., D. Field, P.M. O’Connor, C. Hill, P.D. Cotter, \& R.P. Ross, (2013). Intensive mutagenesis of the nisin hinge leads to the rational design of enhanced derivatives. PLoS One. http://dx.doi.org/10.1371/journal.pone.0079563.

Himeno, K., K.J. Rosengren, T. Inoue, R.H. Perez, M.L. Colgrave, K. Fujita, N. Ishibashi, T. Zendo, P. Wilaipun, V. Leelawatcharamas, H. Jikuya, D.J. Craik \& K. Sonomoto, (2015) Identification, characterization, and the three-dimensiona structure of the novel circular bacteriocin, enterocin NKR-5-3B, from Enterococcus faecium. Biochemistry 54: 4863-4876 http://dx.doi.org/10.1021/acs.biochem.5b00196.

Ishibashi, N., K. Himeno, K. Fujita, Y. Masuda, R.H. Perez, T. Zendo, P.

Wilaipun, V. Leelawatcharamas, J. Nakayama \& K. Sonomoto, (2012) Purification and characterization of multiple bacteriocins and an inducing peptide produced by Enterococcus faecium NKR-5-3 from Thai fermented fish. Bioscience Biotechnology Biochemistry 76: 947-953. http://dx.doi.org/10.1271/bbb.110972.

Islam, M.R., K. Shioya, J. Nagao, M. Nishie, H. Jikuya, T. Zendo, J. Nakayama, \& K. Sonomoto, (2009). Evaluation of essential and variable residues of nukacin ISK-1 by NNK scanning. Mol Microbiol 72, 1438-1447. http://dx.doi.org/10.1111/j.1365-2958.2009.06733.x.

Jacob, A.E., \& S.J. Hobbs, (1974) Conjugal transfer of plasmid-borne multiple antibiotic resistance in Streptococcus faecalis var. zymogenes. Journal of Bacteriology 117: 360-372. http://dx.doi.org/10.1128/JB.117.2.360-372.1974.

Kemperman, R., M. Jonker, A. Nauta, O.P. Kuipers, \& J. Kok, (2003) Functional analysis of the gene cluster involved in production of the bacteriocin circularin A by Clostridium beijerinckii ATCC 25752. Applied Environmental Microbiology 69: 5839-5848. http://dx.doi.org/10.1128/aem.69.10.5839-5848.2003.

Martin-Visscher, L.A., M.J. van Belkum, \& J.C. Vederas, (2011) "Class IIc or Circular Bacteriocins," in Prokaryotic Antimicrobial Peptides: From Genes to Applications, eds. D. Drider and S. Rebuffat (London: Springer), pp. 213-236.

Miller, K.W., R. Schamber, Y. Chen, \& B. Ray, (1998) Production of active chimeric pediocin AcH in Escherichia coli in the absence of processing and secretion genes from the Pediococcus pap operon. Applied Environmental Microbiology 64(4): 1587

Molloy, E.M., D. Field, P.M. O’Connor, P.D. Cotter, C. Hill, R.P Ross, (2013) Saturation mutagenesis of lysine 12 leads to the identification of derivatives of nisin a with enhanced antimicrobial activity. PLoS One http://dx.doi.org/10.1371/journal.pone.0058530.

Niamah, A. K. (2018). Structure, mode of action and application of pediocin natural antimicrobial food preservative: A review. Basrah Journal of Agricultural Sciences, 31(1), 59-69. https://doi.org/10.37077/25200860.2018.76

Perez, R.H., K. Himeno, N. Ishibashi, Y. Masuda, T. Zendo, J. Nakayama, \& K. Sonomoto, (2012) Monitoring of the multiple bacteriocin production by Enterococcus faecium NKR-5-3 through a developed liquid chromatography and mass spectrometry-based quantification system. Journal of Bioscience and Bioengineering 114: 490-496. http://dx.doi.org/10.1016/j.jbiosc.2012.06.003.

Perez, R.H., N. Ishibashi, T. Inoue, K. Himeno, Y. Masuda, N. Sawa, Zendo, J. Nakayama, \& K. Sonomoto, (2016) Functional analysis of the genes involved in the biosynthesis of enterocin NKR-5-3B, a novel circular bacteriocin. Journal of Bacteriology 198: 291-300. http://dx.doi.org/10.1128/JB.00692-15.

Perez R.H., H. Sugino, N. Ishibashi, T. Zendo, P. Wilaipun, V Leelawatcharamas, J. Nakayama, \& K. Sonomoto, (2017). Mutations near the cleavage site of enterocin NKR-5-3B prepeptide reveal new insights into its $\begin{array}{llll}\text { biosynthesis. } & \text { Microbiology. } & 2017 & \text { 163(4):431 }\end{array}$ 441. https://doi.org/10.1099/mic.0.000435

Perez, R.H., T. Zendo, \& K. Sonomoto, (2018) Circular and leaderless bacteriocins: Biosynthesis, mode of action, applications, and prospects. Frontiers in Microbiology 9: 2085. http://dx.doi.org/10.3389/fmicb.2018.02085.

Sambrook, J., \& D.W. Russell, (2001). Molecular cloning: a laboratory manual. 3rd ed. Cold Spring Harbor, N.Y.: Cold Spring Harbor Laboratory Press.

Scott, J.K., \& G.P. Smith, (1990) Searching for peptide ligands with an epitope library. Science 249: 386-390. http://dx.doi.org/10.1126/science.1696028. 